\title{
Optimization of "Internet +" Agricultural Product Industry Chain Based on Partial Differential Equation Inversion Layer by Layer
}

\author{
Tunglai Hu, ${ }^{1}$ Yizi Li $\mathbb{D}^{1,2}$ and Cai Le ${ }^{2}$ \\ ${ }^{1}$ Department of Business Management, National Taipei University of Technology, Taipei 10608, Taiwan \\ ${ }^{2}$ School of Economics \& Management, Huizhou Economics and Polytechnic College, Huizhou, Guangdong 516057, China \\ Correspondence should be addressed to Yizi Li; t102749020@ntut.edu.tw
}

Received 20 December 2021; Revised 18 January 2022; Accepted 19 January 2022; Published 9 February 2022

Academic Editor: Gengxin Sun

Copyright (c) 2022 Tunglai Hu et al. This is an open access article distributed under the Creative Commons Attribution License, which permits unrestricted use, distribution, and reproduction in any medium, provided the original work is properly cited.

With the popularization and maturity of Internet technology, it has become an inevitable trend of agricultural development to transform the way of agricultural development and connect the Internet with agricultural products. The development of "Internet + agriculture" is rearranging the entire agricultural product industry chain and it also affects the direction of agricultural development. In this article, we make full use of Internet technology, aiming at the development status of the agricultural product industry chain, and design a layer-by-layer inversion model based on partial differential equations to construct an "Internet + " agricultural product industry chain optimization system. This research strives to achieve the coupling of hardware infrastructure and software service systems. A system platform consisting of one platform, two modules, five services, and twelve functional submodules is designed, and a layer-by-layer inversion method of partial differential equations is introduced. The optimization of the agricultural product industry chain from the control of the production side and the sales side is realized. On this basis, further analysis of the accuracy of partial differential equations, system response time, greenhouse climate change control, agricultural product production capacity, and brand value are further analyzed. The following five conclusions are drawn: first, the response time of each interface is 1 to 2 seconds and in the interval of 500 milliseconds, the intensive range is the densest, and the system performance is further improved. Second, for the three spatial fractional partial differential equations, the equations used in this system basically achieved the best accuracy results. Third, at 13: 00, the maximum temperature difference between indoor and outdoor is $6.3^{\circ} \mathrm{C}$, which is the moment when the outdoor solar radiation is strongest. The average temperature in the greenhouse is higher than that outdoors, and the trend of the two changes is the same. Fourth, after the optimization of the industrial chain, the highest utilization rate of agricultural product production capacity is $97 \%$ and the net profit can reach $150 \%$. Fifth, the brand value of agricultural products has increased from 560 million Yuan in 2010 to 3.153 billion Yuan in 2020, and the quality value has achieved rapid growth. The results show that the "Internet +" agricultural product industry chain optimization system in this article has a reasonable structure, stable operation, easy expansion, and strong applicability and further accelerates the process of modern agriculture.

\section{Introduction}

With the vigorous development of the Internet, the wave of normalization characterized by information technology and data services is sweeping the world. Mankind is ushering in from commodity economy to knowledge economy, from the industrial society to information society, and from information technology to data technology. The transformation from agriculture to information agriculture is gradually undergoing tremendous changes in production, lifestyles, and ways of thinking [1]. Worldwide, the application of Internet technology in e-commerce, industry, manufacturing, medical care, and education has achieved varying degrees of success. Countries are paying more and more attention to the development of the Internet. The proposal of the "Internet + " action plan has even elevated the development of the Internet to a national strategy. "Internet +" is not only a simple combination and transformation with traditional industries but also an innovation in the way of thinking. According to the industry characteristics of 
different industries, Internet technology is used to achieve the upgrade and transformation of traditional industries so that traditional industries can be automated, networked, and digitized [2].

Agriculture is the foundation of all industries, and the development of agriculture is related to the operation of the entire country and the stability of the economy [3]. With the economy entering a new normal, it is necessary to further intensify and deepen rural reforms, promote the upgrading of traditional agriculture with "Internet + ," realize the industrial innovation and economic transformation of agriculture, and continue to strengthen the foundation of agriculture. "Internet + Agriculture" refers to the crossborder integration of new-generation information technology and agriculture through the use of mobile Internet, big data, cloud computing, and the Internet of Things, transforming, optimizing, and upgrading the traditional aspects of planning, production, sales, service, and finance. The agricultural industry chain forms a full-service system of "a framework, multiple applications, aggregating industries, and serving farmers." Further, it unblocks agricultural market information channels and circulation channels so that the agricultural production, supply, and marketing systems are closely integrated. It significantly improves agricultural production efficiency, quality, and benefits and can realize new modern agricultural products, new models, and new formats based on the Internet platform [4].

The "Internet + agriculture" development model has laid the foundation for further optimizing the agricultural product industry chain and promoted the upgrading of traditional agriculture. This article relies on basic infrastructure and network connections to realize the perception of the environment, is committed to achieving point-tocloud information sharing, data storage, and remote control, and builds an "Internet +" agricultural product industry chain through a layer-by-layer inversion model based on partial differential equations. The system is optimized.

\section{Related Work}

The Internet, also known as the international network, refers to the interconnection network that connects the network and the network in accordance with a certain communication protocol to achieve global coverage [5]. In this network, things at both ends of the network are connected together through a variety of devices. "Internet+" was first proposed in 2012. "Internet+" is a new economic form, that is, to make full use of the advantageous factors of the Internet in the distribution of resources and information, integrate the Internet with all sectors of society, and effectively improve the performance of various industries. The level of innovation and development can create new growth points and finally realize the upgrading of the industry and the long-term economic progress [6]. The essence of the exchange network is the sharing of resources, and "Internet + " is a process of adding innovative elements to the shared resources and online and innovating traditional industries [7]. "Internet + agriculture" is the application of Internet technology to the production, management, circulation, sales, and operation of traditional agriculture so as to realize the information development of traditional agriculture.

The idea of the agricultural product industry chain originated from abroad. Scholars' research on the agricultural product industry chain focused on its information management, value chain analysis, and agricultural product quality control. $\mathrm{Hu}$ et al. proposed the behavioural method of "total quality management" [8]. On this basis, Renda, Andrea, and other scholars proposed to establish an early warning of agricultural product quality with the function of maintaining the reputation of the industry chain and consumer confidence [9]. Wei and Lv, based on a series of researches on information, logistics management, and the organizational structure and market channels of the agricultural industry chain, such as sugarcane, fruits, and vegetables, proposed how to improve industry competition corresponding countermeasures and suggestions for the problem of strength [10]. Khandelwal et al. proposed that information and communication technology can play a great role in developing the agricultural product industry chain. Not only does it help to improve the competitiveness of enterprises in the market, but also it helps enterprises obtain opportunities for market share increase [11]. Kamble et al. proposed that information and communication technology can serve the entire agricultural product industry chain and even more departments, reducing the cost of information search in the industry chain, so the government should bear the cost of its investment and construction [12]. Shi believed that the construction of communication technology and agricultural information chain management should be actively implemented [13]. Torky and Hassanein analyzed the agricultural industry chain from the perspective of the value chain and further clarified that the use of industrial value chain management methods has significant effects such as reducing the cost of enterprises in the production and processing of agricultural products and increasing market share [14].

"Internet + " plays an important role in optimizing the agricultural product industry chain. The use of the "Internet + " model can fully integrate the production, processing, sales, and after-sales links in the production process of agricultural products and the use of Internet technology to improve each link, increase efficiency, and increase output value [15]. In the Internet age, the use of big data to analyze the production of agricultural products can effectively reduce market risks and avoid losses caused by inadequate understanding of the market. In addition to effectively formulating scientific production methods, Internet technology can also construct an informative management model. Real-time monitoring through the Internet, processing the monitored values, and formulating response plans are timely, trouble-free, and labour-saving, which will greatly help large-scale production. Second, Internet technology can effectively expand the added value of agricultural products. In the past, producers of agricultural products, mainly selling raw materials, can use the Internet to understand the direction of related agricultural products processing, learn the production process through the Internet, and move towards high added value. Development in 
a variety of ways, directly benefiting farmers and increasing their income, is of great importance to the realization of my country's agricultural modernization.

Partial differential equations are used to describe many physical and natural phenomena. In industrial and agricultural process control, many models are based on control problems and optimization problems restricted by partial differential equations [16]. However, optimal control problems based on partial differential equations often require a lot of time to solve, which cannot meet the existing optimization and control requirements. Therefore, how to quickly solve partial differential equation models or perform layer-by-layer inversion of partial differential equation models is very important. Compared with a linear regression model, a gray series prediction model, and a neural network model, the layer-by-layer inversion method of partial differential equations is simple to use, has strong versatility, and is more efficient to solve. Therefore, this article adopts the layer-by-layer inversion method of partial differential equations to study the optimization of the agricultural product industry chain.

\section{The Realization of "Internet +" Agricultural Product Industry Chain Optimization}

The introduction of "Internet + " technology provides technical support for real-time monitoring and management of the entire chain of agricultural production, warehousing, logistics, and sales and establishing a new informative agricultural product industry chain optimization system [17]. This chapter introduces the layer-by-layer inversion model of partial differential equations and constructs the "Internet +" agricultural product industry chain optimization system from three aspects: the overall structure design of the industrial chain, the production end industrial chain optimization, and the sales end industrial chain optimization.

3.1. Optimizing the Overall Architecture Design of the Industrial Chain. In the design process of the "Internet +" agricultural product industry chain optimization system, a microservice-based architecture is used to build an application basic framework. The application layer based on the HTTP protocol is divided into web applications on the PC side and mobile applications on the mobile phone. Both interact with services through APIs, and the front and back ends are completely separated. Each service in the microservices can provide services for the PC and mobile terminals at the same time, can start multiple instances when the amount of concurrency is large, and use load balancing to slow down the concurrency. The Internet system architecture can be roughly divided into three layers: the perception layer, the network layer, and the application layer. Each layer of subsystems closely cooperates to form a complete "Internet +" agricultural product industry chain optimization system application platform, as shown in Figure 1.

The perception layer is the key part of information collection and the core of the realization of Internet

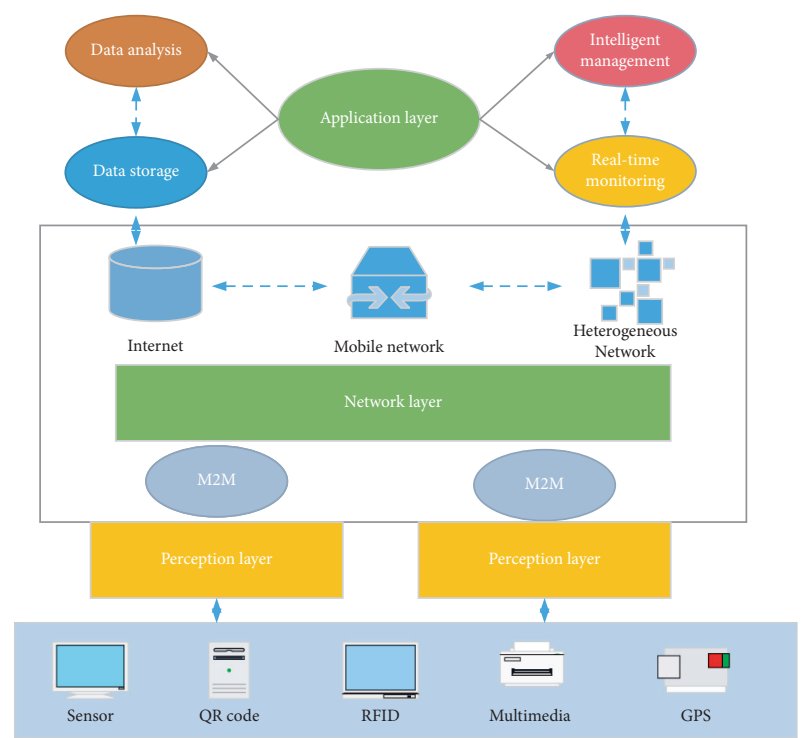

FIGURE 1: Industrial chain optimization system hierarchy diagram.

technology. It is mainly responsible for the intelligent perception and recognition of objects, collection of information, and collaborative information processing [18], including smart devices such as sensors, GPS, RFID readers, electronic tags, multimedia information collection QR codes, and actuators.

The network layer is the bridge between the perception layer and the application layer. It is mainly responsible for the transmission and communication of information; that is, through communication technologies such as the Internet, mobile communication networks, and wireless sensor networks, all kinds of data obtained by the perception layer are barrier-free and highly reliable-high-security transmission to the control centre-fully integrate and expand the existing network, share sensing device data in real time, and manage and authenticate applications and sensing devices.

The application layer is the in-depth integration of various technologies. It mainly completes data analysis, intelligent management, real-time monitoring, data storage, and ordering, forms a resource database that matches business needs, provides various application solutions, and finally realizes the Internet in agricultural products.

\subsection{Industrial Chain Optimization System Composition.} This system has designed a complete set of "Internet +" agricultural product industry chain optimization system from bottom to top with complete facilities, complete functions, interactive friendly, economical, and practical. The system consists of a platform, two modules, five services, and twelve functional modules. The system function hierarchy is shown in Figure 2.

3.2.1. Infrastructure Services. Infrastructure services include wireless sensor networks, greenhouse control systems, and video surveillance systems. The use of a wireless sensor network system can make agricultural production digitized 


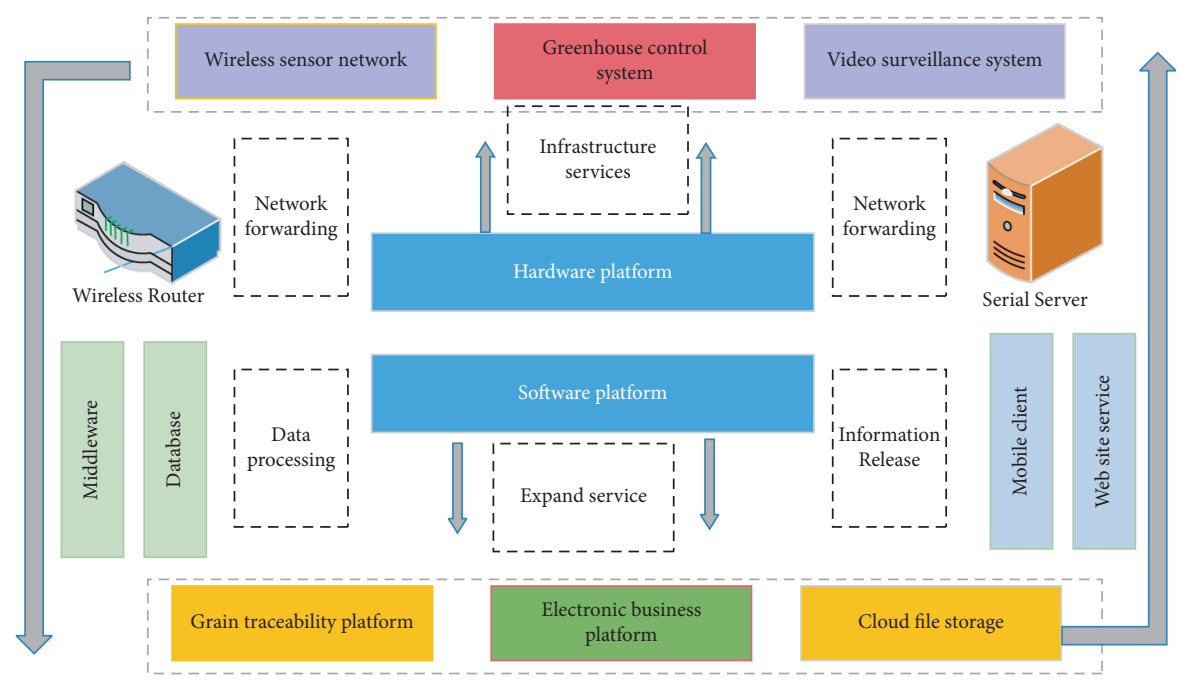

FIgURE 2: Industrial chain optimization system function diagram.

and networked, measuring temperature and humidity in the air, carbon dioxide content and luminance, and temperature and relative water content in the soil. The control system in the greenhouse is controlled by PLC as the core. It is equipped with necessary fuses, air switches, intermediate relays, AC contactors, etc., to complete the effective control of various institutions in the greenhouse; video monitoring system, based on the H.264 image compression standard, combined with night infrared technology and integrated fluorite cloud establishment; an all-weather video surveillance system with complementary Ethernet, Wi-Fi, and mobile communication technologies.

3.2.2. Networking Forwarding Service. The router Internet equipment dynamically allocates IP addresses to the equipment in the LAN, provides the necessary network connection capabilities for the LAN, and realizes the isolation of the internal network and the external network.

Data processing core service program is responsible for undertaking the underlying basic data and upper-level software services so that the functions of each part of the system are closely integrated, and the main functions such as database operation, data analysis, and network communication are realized.

3.2.3. Core Database. It completes the operation of all data in the system, provides the basic "addition, deletion, modification, and query" function, and realizes the storage of environment-aware parameters by establishing different relational tables.

Website server provides a universal management platform for different bases and different users. Android mobile phone client mobile terminal software realizes login authentication of different users, real-time update display of various environmental parameter data, video monitor realtime display, various historical data query, data chart drawing, remote control, and other main functions.
The expansion of the service body includes two major service functions: the agricultural product traceability platform and the agricultural product e-commerce platform. This system provides a common interface for these two services, constructs a complete facility agriculture cloud platform service ecology, and creates a unified platform from planting production to the dining table.

\subsection{Production End Industrial Chain Optimization Control.}

The use of Internet technology on the production side of agricultural products is an important manifestation of "Internet + agriculture." Through computer control, wireless sensing hardware, greenhouse control equipment, and video monitoring equipment are used to achieve one-button operation and intelligent management in each link of agricultural product selection, planting, irrigation, and pest control, as shown in Figure 3.

The agricultural product industry chain system is based on information technology, follows the existing international and domestic standard systems, uses information technology, and uses the SaaS model to create an Internet industry chain optimization module that supports agricultural product planting services and deploys a "production environment monitoring system," "Insect Early Warning and Control System," "Agricultural Technology Guidance System," etc., to achieve various production data for breeding, cultivation, and maintenance, data collection, and related statistical analysis and targeted analysis of growth patterns through the Internet to build perfect growth. The model provides production guidance support for enterprises and realizes the digital, standardized, scientific, and intelligent production management of planting. It integrated closely with the system functional requirements of Internet production management, soil moisture detection, climate monitoring, insect prevention and control early warning, crop spectrum analysis, etc., to build mutually independent modules such as intelligent decisionmaking for agricultural product planting, pest prevention and control, and technical industry chain production assistance. 


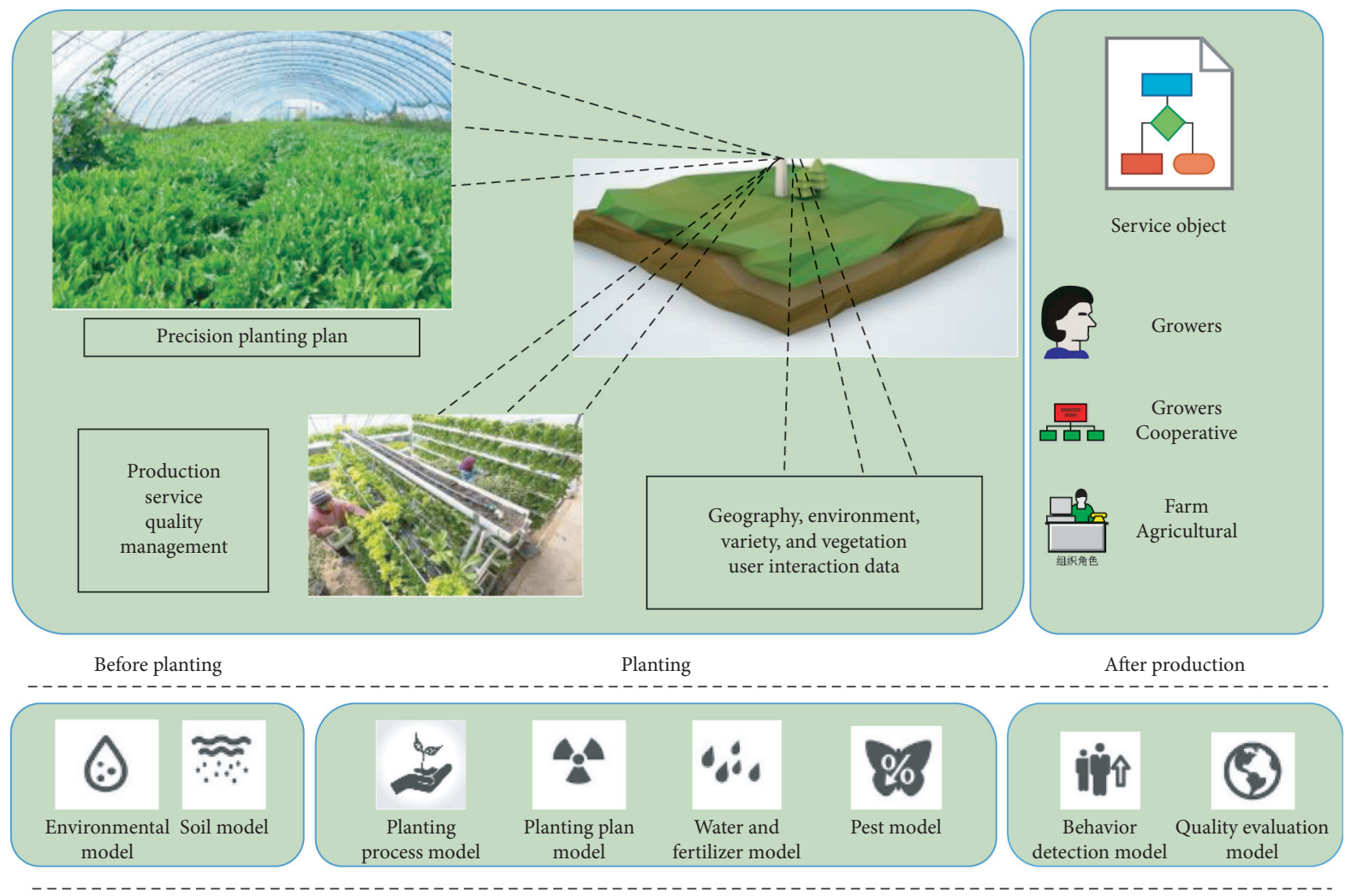

FIgURE 3: Agricultural products production end system diagram.

3.4. Sales End Industrial Chain Optimization Control. "Internet + agriculture" has brought revolutionary changes to the traditional agricultural model. The buying end and the selling end have more independent choices in terms of information acquisition, purchase methods, sales methods, independent choices, and so on. At the same time, it is possible to use the Internet trading platform to sell agricultural products online, to achieve one-stop service from multiple links such as transaction, payment, and distribution, reducing intermediate links and reducing transaction costs, as shown in Figure 4.

The system is an online mobile $\mathrm{B} 2 \mathrm{~B}$ trading platform for agricultural products, which supports users to access at any time using the mobile terminal. The main users of the platform are agricultural product wholesalers and retailers and distribution personnel. The platform mainly provides online trading platforms for wholesalers in urban distribution centres and urban retail companies so as to ensure the normalization of agricultural product supply chains and standardization of transaction procedures and improve the efficiency of transactions between cities. This system provides a convenient mobile electronic trading platform for the trading activities of agricultural products. The entire trading platform consists of two parts: the front-end mobile APP and the back-end management. The mobile APP terminal is divided into the following: product management module, order management module, shopping cart management module, delivery address management module, and product live broadcast module according to the roles of different users. The background management module is mainly divided into the following: personnel management module, merchant management module, commodity management module, warehouse management module, logistics management module, order management module, log audit module, and report module.

\subsection{Layer-by-Layer Inversion Model of Partial Differential} Equations. Partial differential equations refer to equations of unknown functions and their partial derivatives, describing the relationship between independent variables, unknown functions, and partial derivatives of unknown functions [19]. The variables of functions in partial differential equations are about time and space, and phenomena in many fields can be described by such functions. Based on the characteristics of optimal control, strong versatility, and higher solution efficiency of partial differential equations, this article uses partial differential equations to establish agricultural product production environment models and applies the method of layer-by-layer inversion for analysis and evaluation.

\subsubsection{Continuity Equation}

$$
\frac{a p}{a t}+a \times a x_{i}\left(p u_{i}\right)=t_{m}
$$

Here, $t_{\mathrm{m}}$ is the mass added to the continuous phase from the dispersed secondary phase, which can be any custom source term. 


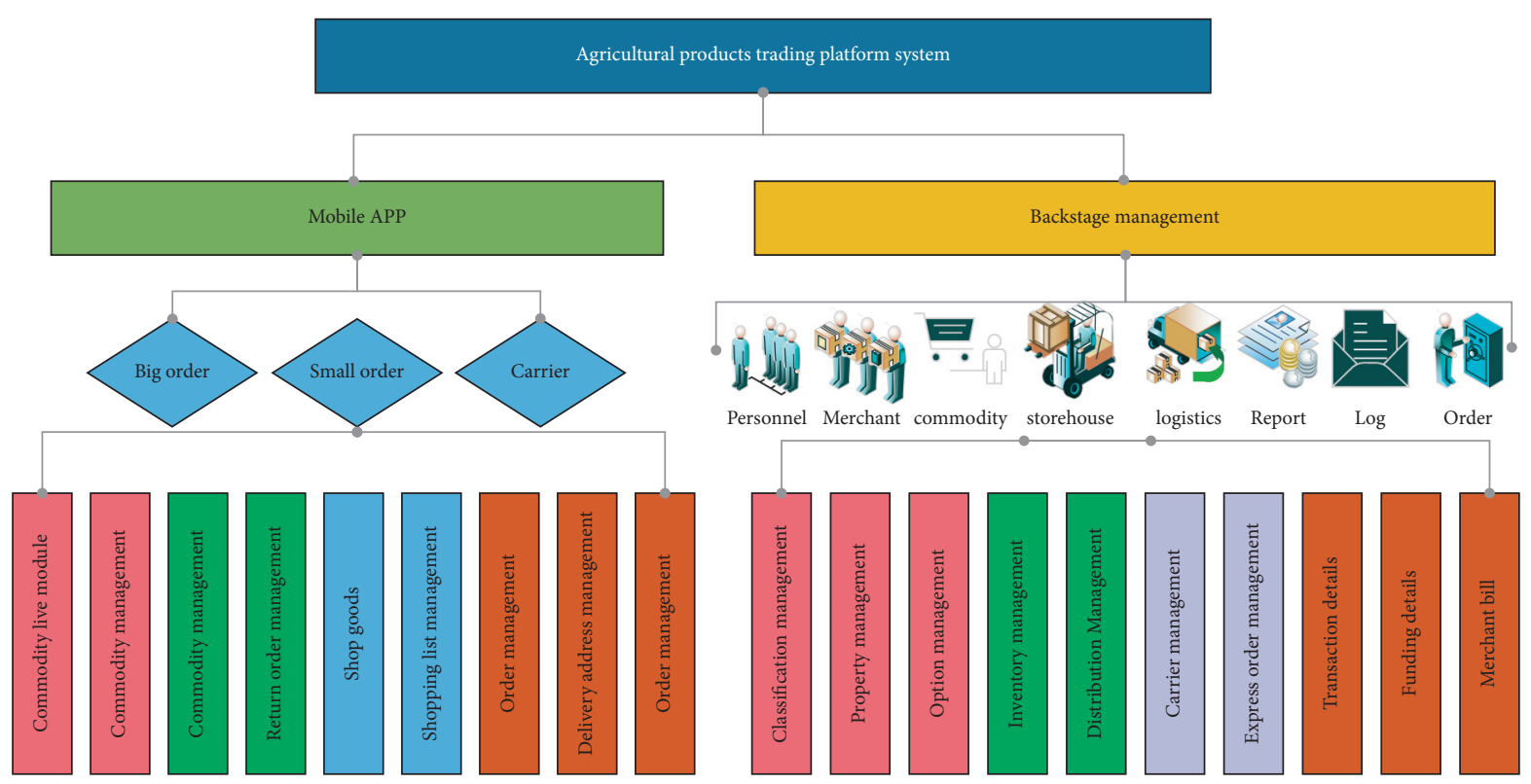

FIgURe 4: Agricultural product trading platform map.

\subsubsection{Momentum Conservation Equation}

$$
\begin{aligned}
a(p u) \times a t+\operatorname{div}(p u u) & =\operatorname{div}(u g r a d u)-a p \times a x+t_{u}, \\
a(p y) \times a t+\operatorname{div}(p v u) & =\operatorname{div}(u g r a d v)-a p \times a x+t_{v}, \\
a(p w) \times a t+\operatorname{div}(p w u) & =\operatorname{div}(u g r a d w)-a p \times a x+t_{w} .
\end{aligned}
$$

Here, $t_{\mathrm{u}}, t_{\mathrm{v}}$, and $t_{\mathrm{w}}$ are the generalized source terms of momentum.

$$
\begin{aligned}
t_{x}= & a \times a x\left(u \frac{a u}{a x}\right)+a \times a y\left(u \frac{a v}{a x}\right)+a \times a z\left(u \frac{a w}{a x}\right) \\
& +a \times a x(\operatorname{divu}), \\
t_{y}= & a \times a x\left(u \frac{a u}{a y}\right)+a \times a y\left(u \frac{a v}{a y}\right)+a \times a z\left(u \frac{a w}{a y}\right) \\
& +a \times a y(\operatorname{divu}), \\
t_{z}= & a \times a x\left(u \frac{a u}{a z}\right)+a \times a y\left(u \frac{a v}{a z}\right)+a \times a z\left(u \frac{a w}{a z}\right) \\
& +a \times a z(\operatorname{divu}) .
\end{aligned}
$$

The viscosity of the air in the greenhouse is constant and can be regarded as an incompressible gas, so $t_{\mathrm{u}}=t_{\mathrm{v}}=t_{\mathrm{w}}=0$. When the wind speed outside the greenhouse is lower than $0.5 \mathrm{~m} / \mathrm{s}$, the driving force of indoor ventilation is mainly thermal pressure ventilation. Therefore, when the indoor air area is divided into a certain number of calculation grids, the volume force acting on each volume grid is only gravity, so $t_{\mathrm{x}}=t_{\mathrm{y}}=t_{\mathrm{z}}$.

\subsubsection{Energy Conservation Equation}

$$
\begin{aligned}
& a \times a t(p E)+a \times a x_{i}\left(u_{i} p E-P\right) \\
& =a \times a x_{i}\left[K_{e f f} \times a T+u_{j}\left(t_{i j}\right)\right]+s_{h} .
\end{aligned}
$$

Here, $K_{e f f}$ is the effective heat transfer coefficient, where $\mathrm{K}$ is the turbulent heat transfer coefficient, which is related to the selected turbulence model. $E$ is the total energy, where $h$ is the sensible enthalpy of the ideal gas, $h$ is the mass fraction of component $j$. $J$ is the transport of enthalpy in the process of mixed air transport; $S$ is the volume heat source term.

3.5.4. Component Transmission Equation. In the convection and diffusion of multiple substances, the mass fraction $Y_{\mathrm{i}}$ of the $i$ substance satisfies the composition conservation equation.

$$
a \times a t\left(p Y_{i}\right)+\Delta \cdot\left(p v Y_{i}\right)=\Delta J_{i}-Q_{I}-T_{i} .
$$

Here, $Q$ is the net production rate of the chemical reaction; $T$ is the additional production rate caused by the discrete phase and user-defined source terms. $J$ is the diffusion flux of the substance.

In turbulent flow, the mass diffusion flux is calculated according to the following formula:

$$
J_{I}=-\left(p D_{i m}\right)+u_{t} \times S c t \cdot \Delta Y_{i}
$$

Here, Sct is the turbulent Schmidt number.

In order to solve the temperature of the humid air, the enthalpy of the humid air must be solved, which satisfies the following energy conservation equation: 


$$
\begin{aligned}
& a \times a t(p h)+a \times a x(p u h)+a \times a y(p v h) \\
& =a \times a x(a h \cdot a x)+s_{h} .
\end{aligned}
$$

The mass concentration $\mathrm{Y}$ of water vapor in humid air satisfies the following mass conservation equation:

$$
\begin{aligned}
& a \times a t(p Y)+a \times a x(p u Y)+a \times a y(p v Y) \\
& =a \times a x(a Y \cdot a x)+s_{c} .
\end{aligned}
$$

The mass concentration of water vapor has the following relationship with the moisture content:

$$
Y_{W}=d_{w} \times\left(1+d_{w}\right) .
$$

Here, $d_{\mathrm{w}}$ is the moisture content of humid air, which can be obtained by checking the humidity map.

\section{Analysis on Optimization of "Internet + " Agricultural Products Industry Chain}

In this article, by introducing the layer-by-layer inversion method of partial differential equations, the optimization of the agricultural product industry chain is realized from the control of the production end and sales end. Based on the above, this chapter further analyzes and studies the system response time, the accuracy of partial differential equations, the control of greenhouse climate change, the production capacity of agricultural products, and the brand value.

4.1. System Response Time Test. After the user logs into the APP, the APIs that are accessed most frequently are the product classification interface and the product-related interface. These interfaces need to be accessed by logged-in users, so the HTTP Header Manager component is added to the $J$ Meter test plan, and Authorization and Content-Type are defined in the HTTP Header.

It can be seen from Figure 5 that when the time interval is set to 1000 milliseconds, the response time is within 2 seconds; when the time interval is set to 500 milliseconds, the response time of two interfaces has exceeded 3 seconds. However, the response time is mostly between 1 and 2 seconds. In the interval of 1 to 2 seconds, the range of 500 milliseconds is the densest. According to the result analysis, the adjusted system has effectively improved the average response time.

4.2. Precision Analysis of Partial Differential Equations. For the three spatial fractional partial differential equations, UQPINN(MN), PINN(MN), and TD-Net, the equations used in this system basically achieved the best accuracy results. The experimental results are shown in Figure 6.

On the three different spatial fractional partial differential equations used in this experiment, TD-Net achieved the best average accuracy with the shortest training time. Compared with the second-best training efficiency PINN $(\mathrm{MN})$, when $\alpha=1.2$, TD-Net speeds up by $77.630 \%, 86.319 \%$, and $78.910 \%$ at $0 \%, 1 \%$, and $10 \%$ noise intensity, respectively; when $\alpha=1.4$, TD-Net speeds up by $80.653 \%, 79.732 \%$, and $78.991 \%$ at $0 \%, 1 \%$, and $10 \%$ noise intensity, respectively; when $\alpha=1.6$, TD-Net speeds up at $0 \%, 1 \%$, and $10 \%$ noise intensity, respectively, by $78.197 \%, 80.008 \%$, and $79.643 \%$; when $\alpha=1.8$, TD-Net speeds up by $81.237 \%$, $89.860 \%$, and $79.407 \%$ at $0 \%, 1 \%$, and $10 \%$ noise intensity, respectively.

4.3. Greenhouse Climate Change Response. Taking glass greenhouses planted with crops as the research object, measuring indoor and outdoor environmental factors as boundary conditions, using technology to construct calculation models under different ventilation layouts to analyze the interaction relationship between the greenhouse-crop-environment system, and through specific greenhouse environmental control measures, the environmental parameters of crop growth and development can be optimized.

Figure 7 shows the average temperature and humidity changes inside and outside the greenhouse during the period of 8:00 to 16:00. It can be found that the average temperature in the greenhouse is higher than that in the outdoor during the test period, and the trend of the two changes is the same. At 13:00, the maximum temperature difference between indoor and outdoor is $6.3^{\circ} \mathrm{C}$, which is the time when the outdoor solar radiation is strongest. It can be seen that solar radiation has an important impact on the thermal environment of the greenhouse. The relative humidity indoors is slightly higher than that outdoors. The maximum difference between the two in the morning is $6 \%$, and the two are basically close at noon. On the one hand, the increase in outdoor solar radiation leads to a decrease in humidity. On the other hand, the ground in the greenhouse is covered with plastic film, which greatly reduces the influence of water vapor released by soil evaporation on indoor humidity. When the radiation intensity is the strongest in the day, correspondingly, the indoor and outdoor temperatures also become the highest, while the relative humidity is the lowest. It can be seen that when there is no heat source in the greenhouse, solar radiation is the main factor that causes the greenhouse to warm up. The change of temperature and relative humidity is the opposite: high temperature means low relative humidity and low temperature means high relative humidity.

\subsection{Comparative Analysis of Agricultural Production} Capacity. The overcapacity of agricultural products means that if the capacity to produce products is saturated, the products produced will exceed the capacity required by society [20]. The overcapacity of agricultural products is often a false phenomenon. Often farmers sell products cheaply, but urban residents cannot buy cheap agricultural products. This summary study analyzes the production capacity of agricultural products under the condition of optimizing the logistics end of the industrial chain.

It can be seen from Figure 8 that the highest utilization rate of production capacity in the Internet + model is $97 \%$; from the profit analysis, after the implementation of the Internet + model, the sales revenue and profit of agricultural products show a continuous growth trend, and the net profit 

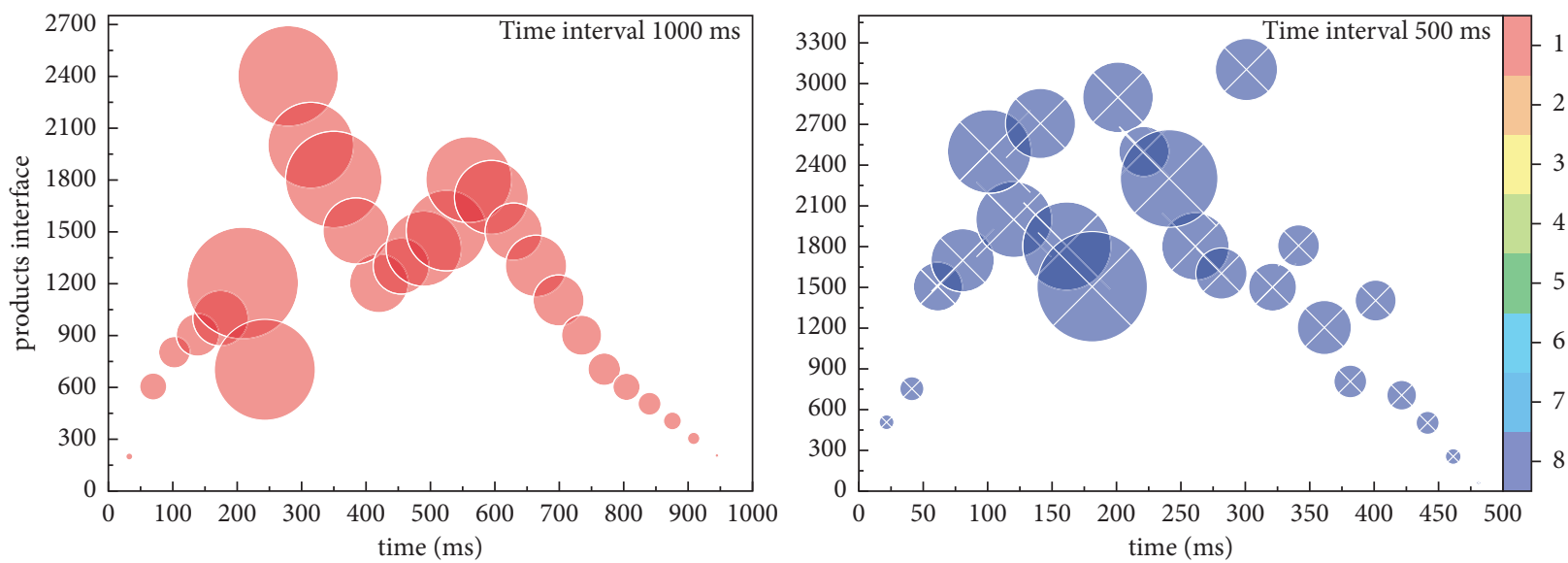

Figure 5: System interface response time test.
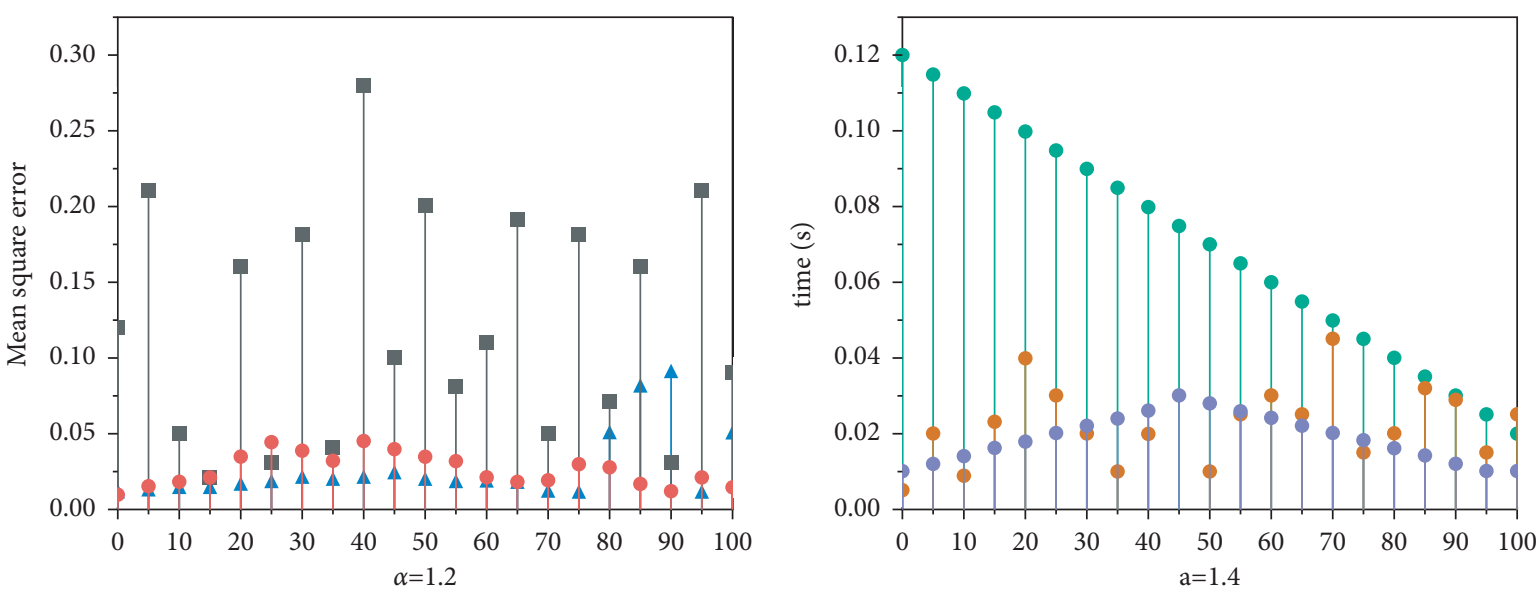

- PINN

- PINN

- UQPINN

- TD-Net
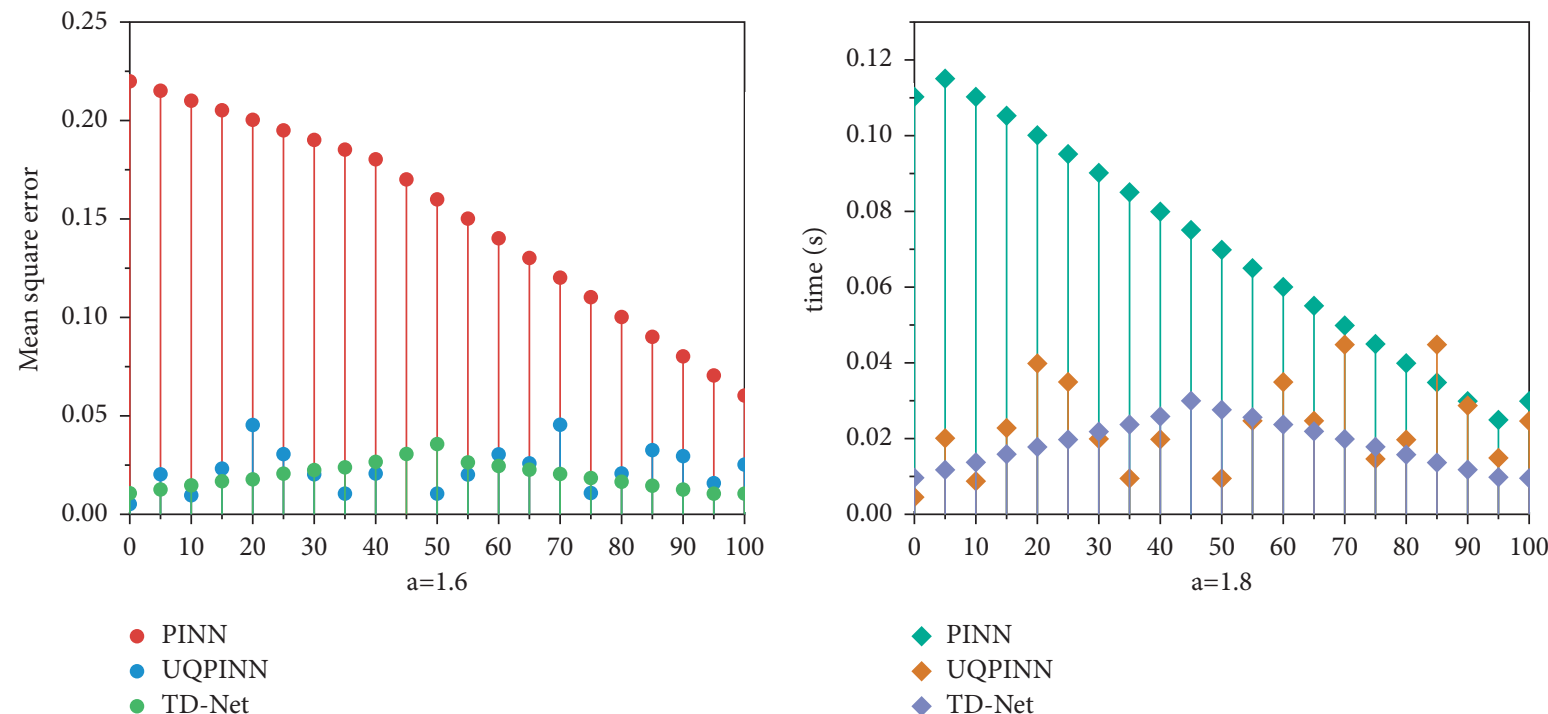

Figure 6: Partial differential equation accuracy test. 

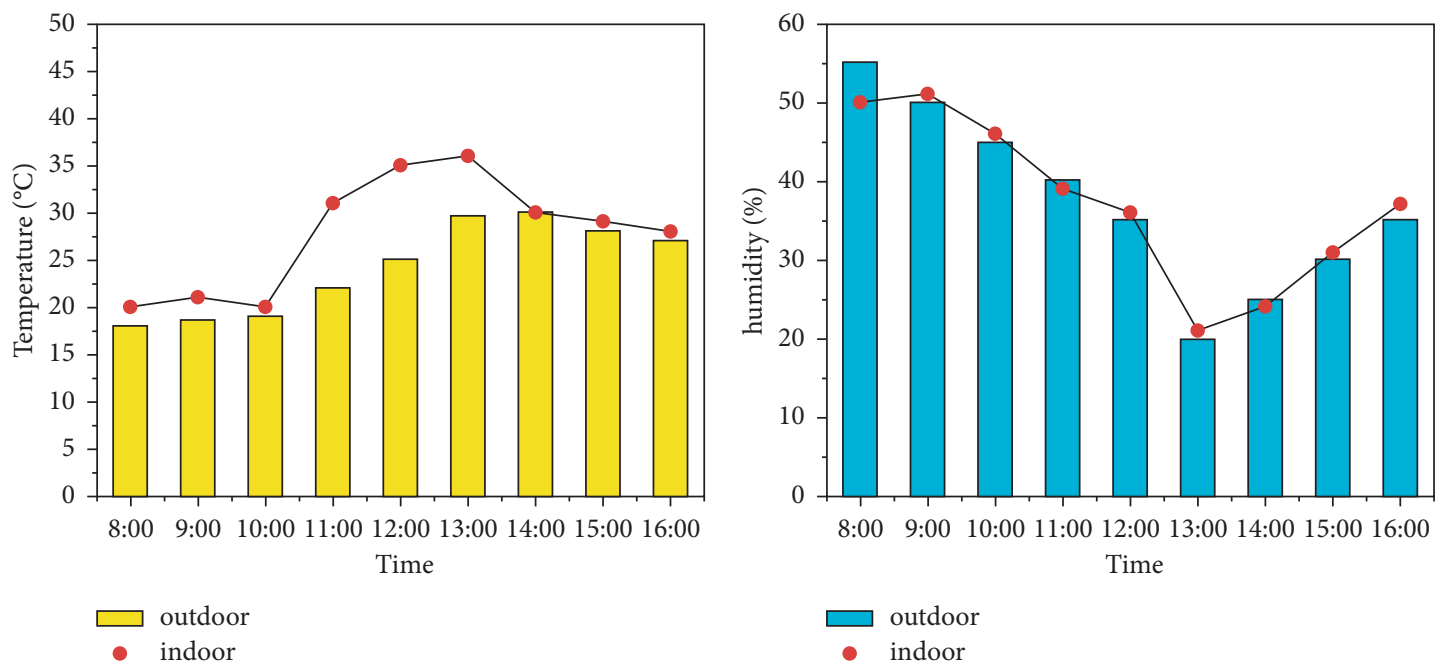

FIgURE 7: Comparison of indoor and outdoor temperature and humidity of crops.
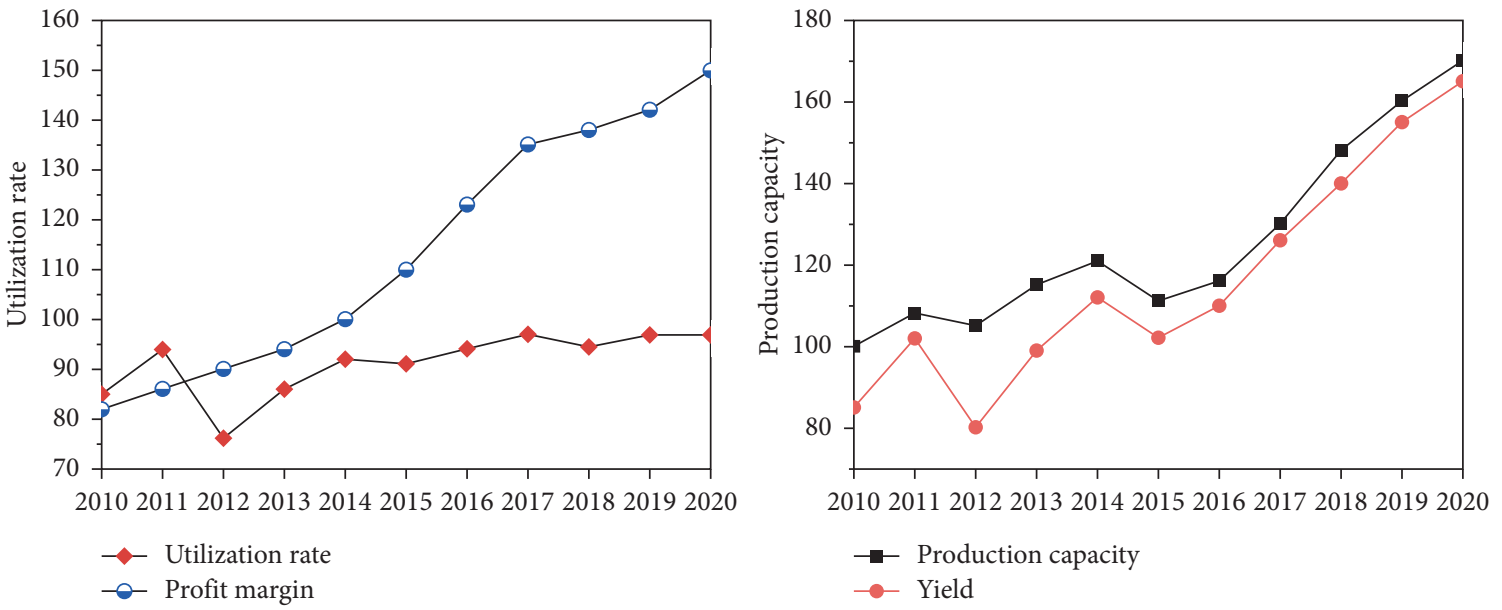

FIgURE 8: Analysis of agricultural product capacity, yield, and profit.

wholesalers, retailers, and other circulation links; each circulation link must obtain its own benefits, which greatly increases the sales cost of agricultural products. After the use of "Internet +" to optimize the industrial chain, the circulation links are continuously reduced, and the direct meeting of production and sales can basically be realized, which reduces the cost of sales. At the same time, the investment in communication channels, the equivalence of market information, and the improvement of product quality have all contributed to the continuous growth of income.

4.5. Analysis of the Realization Value of Agricultural Products. The improvement of the agricultural product industry chain is the improvement of the overall quality, which is reflected in the high level of knowledge, high information, high capital content, and added value of all links in the industry chain [21]. At both ends of the smiling curve, the upstream link of agricultural technology and agricultural materials (seeding technology research and development and supply) and the downstream link of deep processing and sales (agricultural products deep processing, brand building, and marketing network) links have relatively high profit levels. On the other hand, the agricultural production in the middle has a low profit level (the profit level is lower in the links of agricultural product planting, livestock and poultry breeding, and agricultural product primary processing). After product A uses the "Internet + " industry chain platform, the product value is increased from 2010 to 2020 , as shown in Figure 9.

It can be seen from Figure 9 that the brand value of the agricultural product A has increased from 560 million Yuan in 2010 to 3.153 billion Yuan in 2020, showing a growing trend. The 10 -year growth rate reached $463 \%$, and the quality value achieved rapid growth. The development of preproduction varieties and seedling technology, the supply of high-quality and safe agricultural materials, the research and development of postproduction deep processing products, the establishment of independent brands, and the realization 


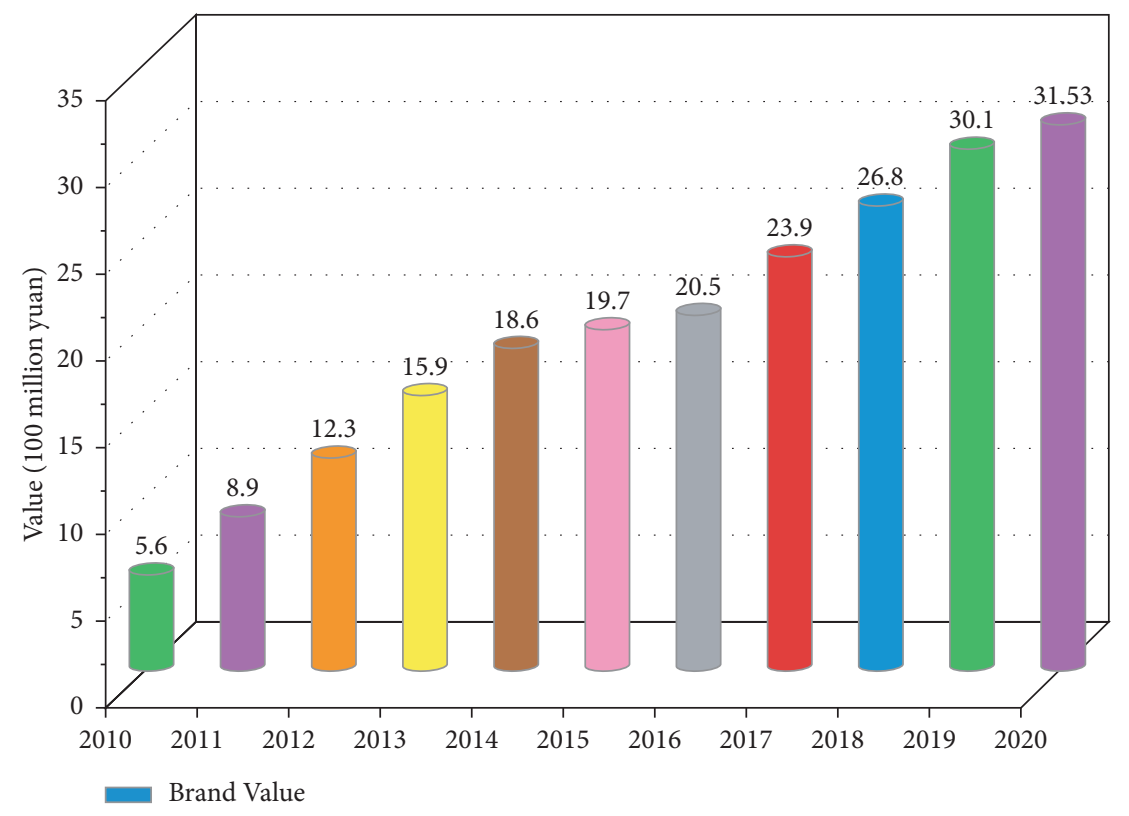

FIGURE 9: Increasing trend of the brand value of agricultural products.

of brand marketing and other industrial chain optimization play a key role in the growth of brand value. The "Internet +" industry chain platform has played a crucial role in enhancing brand value.

\section{Conclusion}

In summary, the integration of "Internet+" with agricultural product production and management will be an inevitable trend in future agricultural development. "Internet+" optimizes the agricultural product industry chain through the flow of information through all links of the industry chain and affects the whole. This article builds the "Internet + " agricultural product industry chain optimization system based on the layer-by-layer inversion model of partial differential equations. A system platform consisting of one platform, two modules, five services, and twelve functional submodules was designed to optimize the agricultural product industry chain from the control of the production and sales ends. Finally, it is concluded that the algorithm accuracy of this system is up to $89.86 \%$, and the system response time is the fastest in the range of 500 milliseconds. The combination of production and sales of agricultural products is realized from the optimized production end and sales end of the industrial chain, and the income of agricultural products increases by up to $150 \%$. This system further enhances the brand value of agricultural products.

The design of this system basically realizes the optimization of "Internet" + agricultural product industry chain, but there are still some shortcomings. Incorporating all agricultural products into the optimization of the industrial chain and realizing the real integration from the field to the platform have become the main problems.

\section{Data Availability}

The data used to support the findings of this study are available from the corresponding author upon request.

\section{Conflicts of Interest}

The authors declare that they have no conflicts of interest.

\section{Acknowledgments}

This work was supported by the National Taipei University of Technology.

\section{References}

[1] A. Sinha, G. Shrivastava, and P. Kumar, "Architecting usercentric internet of things for smart agriculture," Sustainable Computing: Informatics and Systems, vol. 23, no. 19, pp. 88$102,2019$.

[2] K. Leng, "Research on agricultural products supply chain inspection system based on internet of things," Cluster Computing, vol. 22, no. 4, pp. 8919-8927, 2019.

[3] Q. Shen, J. Zhang, Y.-x. Hou, J.-h. Yu, and J.-y. Hu, "Quality control of the agricultural products supply chain based on "Internet+"," Information Processing in agriculture, vol. 5, no. 3, pp. 394-400, 2018.

[4] J. Han, "A model for joint planning of production and distribution of fresh produce in agricultural internet of things," IEEE Internet of Things Journal, vol. 8, no. 12, pp. 9683-9696, 2020.

[5] B. Yan, X. Wang, and P. Shi, "Risk assessment and control of agricultural supply chains under Internet of Things," Agrekon, vol. 56, no. 1, pp. 1-12, 2017.

[6] D. Raba, "Combining the internet of things with simulationbased optimization to enhance logistics in an Agra-food supply chain," in Proceedings of the 2019 Winter Simulation 
Conference (WSC), vol. 23, no. 11, pp. 128-136, IEEE, National Harbor, MD, USA, December 2019.

[7] A. Tzounis, N. Katsoulas, T. Bartzanas, and C. Kittas, "Internet of Things in agriculture, recent advances and future challenges," Biosystems Engineering, vol. 164, no. 13, pp. 31-48, 2017.

[8] X. Hu, L. Sun, Y. Zhou, and J. Ruan, "Review of operational management in intelligent agriculture based on the Internet of Things," Frontiers of Engineering Management, vol. 7, no. 3, pp. 309-322, 2020.

[9] A. Renda, "The age of foodtech: optimizing the agri-food chain with digital technologies," Achieving the Sustainable Development Goals Through Sustainable Food Systems, Springer, vol. 16, no. 23, , pp. 171-187, Cham, Switzerland, 2019.

[10] J. Wei and S. Lv, "Research on the distribution system of agricultural products cold chain logistics based on internet of things," IOP Conference Series: Earth and Environmental Science, vol. 237, no. 5, pp. 56-68, 2019.

[11] C. Khandelwal, M. Singhal, G. Gaurav, G. S. Dangayach, and M. L. Meena, "Agriculture supply chain management: a review (2010-2020)," Materials Today Proceedings, vol. 47, no. 26, pp. 3144-3153, 2021.

[12] S. S. Kamble, A. Gunasekaran, and S. A. Gawankar, "Achieving sustainable performance in a data-driven agriculture supply chain: a review for research and applications," International Journal of Production Economics, vol. 219, no. 89, pp. 179-194, 2020.

[13] X. Shi, "State-of-the-art internet of things in protected agriculture," Sensors, vol. 19, no. 8, pp. 18-33, 2019.

[14] M. Torky and A. E. Hassanein, "Integrating blockchain and the internet of things in precision agriculture: analysis, opportunities, and challenges," Computers and Electronics in Agriculture, vol. 183, no. 59, pp. 405-476, 2020.

[15] S. P. Srinivasan, D. Sorna Shanthi, and A. V. Anand, "Inventory transparency for agricultural produce through IOT," IOP Conference Series: Materials Science and Engineering, vol. 211, no. 7, pp. 996-1010, 2017.

[16] D. Lu, "Elzaki projected differential transform method for fractional order system of linear and nonlinear fractional partial differential equation," Fractals, vol. 26, no. 3, pp. 185-241, 2018.

[17] M. Lezoche, "Agri-food 4.0: a survey of the supply chains and technologies for the future agriculture," Computers in Industry, vol. 117, no. 2, pp. 103-187, 2020.

[18] A. Banasik, "Closing loops in agricultural supply chains using multi-objective optimization: a case study of an industrial mushroom supply chain," International Journal of Production Economics, vol. 183, no. 23, pp. 109-119, 2017.

[19] W. E. Soto-Silva, M. C. González-Araya, M. A. OlivaFernández, and L. M. Plà-Aragonés, "Optimizing fresh food logistics for processing: application for a large Chilean apple supply chain," Computers and Electronics in Agriculture, vol. 136, no. 21, pp. 42-57, 2017.

[20] O. Pavlenko, N. Shramenko, and D. Muzylyov, "Logistics optimization of agricultural products supply to the European Union based on modelling by Petri nets," in Proceedings of the International Conference" New Technologies, Development and Applications, vol. 60, no. 12, pp. 1871-1888, Sarajevo, Bosnia and Herzegovina, June 2020.

[21] A. Cheraghalipour, M. M. Paydar, and M. HajiaghaeiKeshteli, "A bi-objective optimization for citrus closed-loop supply chain using Pareto-based algorithms," Applied Soft Computing, vol. 69, no. 10, pp. 123-135, 2018. 